\title{
Trial Elements Domain
}

National Cancer Institute

\section{Source}

National Cancer Institute. Trial Elements Domain. NCI Thesaurus. Code C49619.

A subject domain utilized for the submission of information encompassing and representing data, vocabulary or records related to trial element. 